\title{
Forage allowances offered to pregnant ewes until middle and late gestation: Organ priorities on foetus development
}

\author{
M. J. Abud ${ }^{1 \#}$, A. Bielli², J. Ithurralde', A. Freitas-de-Melo³, A. Álvarez-Oxiley¹, Á. López-Pérez¹, R. \\ Ungerfeld ${ }^{4} \&$ R. Pérez-Clariget ${ }^{1}$ \\ 1'Departamento de Producción Animal y Pasturas, Facultad de Agronomía, Universidad de la República, Garzón 780, 12900, \\ Montevideo, Uruguay \\ 2Departamento de Morfología y Desarrollo, Facultad de Veterinaria, Universidad de la República, A. Lasplaces 1550, 11600, \\ Montevideo, Uruguay \\ ${ }^{3}$ Departamento de Biología Celular y Molecular, Facultad de Veterinaria, Universidad de la República, A. Lasplaces 1550, \\ 11600, Montevideo, Uruguay \\ ${ }^{4}$ Departamento de Fisiología, Facultad de Veterinaria, Universidad de la República, A. Lasplaces 1550, 11600, Montevideo, \\ Uruguay
}

(Submitted 22 May 2018; Accepted 17 March 2020; First published online 2 August 2020)

\author{
Copyright resides with the authors in terms of the Creative Commons Attribution 4.0 South African Licence. \\ See: http://creativecommons.org/licenses/by/4.0/za \\ Condition of use: The user may copy, distribute, transmit and adapt the work, but must recognise the authors and the South African Journal \\ of Animal Science.
}

\begin{abstract}
Effect of forage allowance before conception and until mid or late gestation was evaluated for effects on foetal and neonatal weights, carcass, nervous systems, metabolic and reproductive organ weights, body dimensions, and variation in intensity of the effects among organs. Effects of two forage allowances, HFA: high forage allowance $(2.9-3.8 \mathrm{~kg}$ of dry matter (DM)/kg bodyweight (BW)) and LFA: low forage allowance $(1.4-2.6$ $\mathrm{kg} \mathrm{DM} / \mathrm{kg} \mathrm{BW}$ ) were evaluated from 23 days before conception until 70 or 122 days postpartum. On gestation day 70, nine ewes per treatment, each carrying one male foetus, were euthanized and their foetuses were removed. The foetuses were weighed, their carcass and organ weights were recorded, and their external genitalia dimensions were measured. Nine additional lambs per treatment were euthanized 12 hours after birth and the same data were recorded. Hearts from day 70 LFA foetuses were lighter, their external genitalia were smaller, and their foetal weight tended to be less than in HFA. Newborn lambs from LFA ewes had lighter carcasses, livers, kidneys, adrenal glands and testes, shorter penises, but higher brain to liver weight ratios than in HFA. The cerebellum, brain, and heart weights of LFA and HFA newborn lambs did not differ. Low forage allowance until late gestation influenced both foetal and lamb weights and affected organ weights differentially. Thus, the treatments induced differences in prioritization of nutrients, with the central nervous system receiving the highest priority, and carcass and external genitalia the lowest.
\end{abstract}

Keywords: foetal programming, intrauterine growth restriction, lambs, undernutrition

\#Corresponding author. Email: mariabudclariget@gmail.com

\section{Introduction}

Maternal undernutrition during gestation induces foetal intrauterine growth restriction (IUGR), which leads to morphological, functional and metabolic alterations that trigger permanent negative consequences in adult life (Barker, 2003; Calkins \& Devaskar, 2011). The causes of IUGR are diverse. It can be the consequence of limited foetal perfusion and restricted nutrient delivery (Fowden \& Forhead, 2004; Xu et al., 2006). Under hypoxemic conditions, the foetus prioritizes the distribution of oxygen and nutrients to vital organs, including the brain, through a pronounced redistribution of both the foetal and placental blood flow and vasculature (Nathanielsz \& Hanson, 2003). This prioritization of the central nervous system development, known as the 'brain-sparing effect', was first described in human beings (Rudolph, 1984) and later associated to IUGR in other mammals 
(Vuguin, 2007; Metges et al., 2012; Torres-Rovira et al., 2013). Furthermore, when maternal undernutrition occurs during gestation, organs that are relevant to animal productivity, such as skeletal muscles and genital organs, receive low priority in nutrient partitioning (Caton \& Hess, 2010).

Gestational undernutrition affects the development of organs in the sheep foetus negatively, including the liver (Gao et al., 2014), brain, kidneys, heart, gut, thymus, pancreas and semitendinosus muscle (Osgerby et al., 2002). In lambs, negative consequences were also observed in the testicular size (Bielli et al., 2001), and in the weight and quality of the carcass (Kenyon \& Blair, 2014). However, limited studies compare the effects of gestational undernutrition on main organ development, which could have consequences in foetal and neonatal stages. Pillai et al. (2017) reported that maternal undernutrition reduces foetal liver weight at day 45 of gestation, and increases the amount of perirenal fat at birth. Furthermore, it is not known whether maternal undernutrition affects other organs and systems differently during foetal growth. Therefore, the comparison of the relative weights of various organs at different developmental stages could enlighten on the organ growth prioritization strategies that prevail under restricted nutrient conditions.

Most sheep production systems in subtropical and temperate regions are based on grazing of natural grasslands, which are characterized by seasonal variations in the quantity and quality of forage. The lowest forage production period (late autumn and winter) often coincides with the pregnancy of ewes (Bermúdez \& Ayala, 2005), thus limiting their nutrient intake (Freitas-de-Melo et al., 2017). Under this environment of limited feed availability, maternal undernutrition and foetal IUGR both occur. The authors' hypothesis was that in IUGR conditions foetuses prioritize key organs, such as the central nervous system and the heart, thus affecting them less than the genital organs and carcass. Thus, the current objectives were to determine the effect of a low forage allowance of natural grassland from 23 days before conception to day 70 or day 122 of gestation on i) foetal and neonatal bodyweights, carcass and main organ weights and external genitalia size, and ii) neonatal body dimensions, brain to liver weight ratio and growth index.

\section{Materials and Methods}

All the procedures performed in animals were in accordance with the ethical standards of the Comisión de Ética en el Uso de Animales (CEUA) (Resolution number 477), Facultad de Agronomía, Universidad de la República, Uruguay. The experiment was conducted at Estación Experimental Bernardo Rosengurtt, Facultad de Agronomía, Universidad de la República, Cerro Largo, Uruguay ( $31^{\circ} 5^{\prime} \mathrm{S}, 54^{\circ} 15^{\prime} \mathrm{W}$ ), from March (late summer) to September (late winter).

In April (autumn), oestrus was synchronized with two doses of a PGF2 $\alpha$ analogue (10 mg, Dinoprost tromethamine, Lutalyse, Pfizer, Kalamazoo, MI, USA), with the second dose being injected 10 days after the first. Ewes were joined with vasectomized rams with marking paint on their chests (1 male per 10 ewes) and were checked twice a day. Marked ewes were inseminated transcervically (day 0) with fresh semen from one of three rams. Pregnancy was verified and number of foetuses was determined by transrectal ultrasound on day 30 (Aloka ProSound 2, Aloka Co., Ltd., Tokio, Japan, equipped with a $7.5 \mathrm{Mhz}$ probe). On day 60, foetal sex was similarly diagnosed. Only ewes that carried a single male foetus were included in the experiment.

Overall, 36 multiparous Corriedale ewes, weighing $45.9 \pm 0.5 \mathrm{~kg}$ (mean $\pm \mathrm{SEM}$ ), and with a body condition score (BCS) of $2.7 \pm 0.04$ (score 1 = emaciated, to $5=$ obese) (Jefferies, 1961) were used in a completely randomized block design. Based on their bodyweight (BW) and BCS, 23 days before conception ewes were randomly assigned to one of two nutritional treatments: i) high forage allowance (HFA) $(n=18)$, ewes grazed on natural grassland at $2.9 \mathrm{~kg}$ dry matter (DM)/kg BW (from day -23 to day 96) from autumn to early winter (March to June) to $3.8 \mathrm{~kg} \mathrm{DM} / \mathrm{kg} \mathrm{BW}$ (from day 96 to day 122) in winter (July); and ii) low forage allowance (LFA) ( $\mathrm{n}=$ 18 ), in which ewes grazed on natural grassland at $1.4 \mathrm{~kg} \mathrm{DM} / \mathrm{kg} \mathrm{BW}$ to $2.6 \mathrm{~kg} \mathrm{DM} / \mathrm{kg}$ of BW. Forage allowance changed in the same gestation period as for HFA ewes. Pregnant ewes grazed on 32 ha of natural grassland, which was divided into three blocks, which were further divided into two plots each with electric fences. Thus, each treatment was repeated on three plots. Animals had free access to water.

On day 70, nine HFA and nine LFA ewes (three from each plot of each treatment) were euthanized with a captive bolt pistol, followed by immediate bleeding. Then the uterus and foetus were removed. The other nine HFA and nine LFA ewes remained in the same treatments until shearing on day 122 . Thereafter all ewes grazed together on Festuca arundinacea with $2.8 \mathrm{~kg} \mathrm{DM} / \mathrm{kg}$ BW until day 145 . From day 116 until lambing, when the demands of the growing foetus and the risk of toxaemia were maximum, all ewes were offered $200 \mathrm{~g} /$ animal/day of rice bran and $50 \mathrm{~mL}$ of glycerine/animal/day to improve their level of nutrition (Sargison, 2007). Ewes were moved to natural grassland paddocks of approximately 1 ha on day 145, where births were recorded 
continuously (Freitas-de-Melo et al., 2015). The 18 newborn lambs were euthanized 12 hours after birth (intravenous injection of sodium thiopental, Richmond, División Veterinaria SA, Buenos Aires, Argentina).

The predominant pasture species were from the Stipa, Paspalum, Bromus, Coelorachis, Piptochaetium, Cynodon, Cardus, Bothriochloa, and Andropogon genera. Forage allowance was adjusted every 30 days by including or removing 'put-and-take' ewes from each paddock according to their bodyweight (Freitas-de-Melo et al., 2015). Forage was trimmed from every plot to quantify DM availability/ha. Total forage availability $(\mathrm{kg} D M / \mathrm{ha})$ was estimated by the double-sampling method (Haydock \& Shaw, 1975). A five-point scale was used, which was estimated by visual assessment, accounting for topography and forage heterogeneity, with three repetitions per scale point (Freitas-de-Melo et al., 2015). Forage allowance ( $\mathrm{kg} \mathrm{DM} / \mathrm{kg}$ animal BW) was estimated according to Sollenberger et al. (2005). Representative forage samples were collected at the beginning of the study and in winter to analyse its chemical composition. The percentages of DM, ash, crude protein (CP) (AOAC, 2007), neutral detergent fibre (NDF), and acid detergent fibre (ADF) of the organic matter were determined using ANKOM technology (Van Soest et al., 1991).

Food intake/ewe/day was estimated as the difference between forage availability and the remnant of forage, which was the available amount for the following month. The pasture growth rate was calculated with mobile cages (Berretta, 1993) and added to the month value. The energy content of the grazed forage was estimated as metabolizable energy $(\mathrm{ME}, \mathrm{MJ} / \mathrm{kg} \mathrm{DM})=[3.2534-(0.0308 \times \mathrm{ADF})] \times 4.184(\mathrm{NRC}, 2007)$. The metabolizable energy provided by the rice bran and glycerine was estimated from tables of Fundación Española para el Desarrollo de la Nutrición Animal (2010). The protein and energy requirements were based on the 1985 and 2007 NRC tables, respectively.

Availability and height of the Festuca arundinacea prairie were $1360.68 \pm 77.74 \mathrm{~kg} \mathrm{DM} / \mathrm{ha}$ and $13.20 \pm$ $0.75 \mathrm{~cm}$, respectively. The chemical composition was $12.55 \% \mathrm{CP}, 48.59 \% \mathrm{NDF}, 22.56 \% \mathrm{ADF}$, and $10.82 \%$ ash, while the chemical composition of rice bran was $88 \%$ DM, 14\% CP, 9\% ADF and 24\% NDF. The composition of glycerine was $3 \%$ water, $6 \%$ ash, $77 \%$ glycerol (AOCS, 2012), 13\% fat (AOAC, 2007), and 1\% methanol (ALUR, Uruguay). Energy and protein requirements covered by the fescue prairie plus supplementation were $202 \%$ and $160 \%$, respectively. The mean forage allowance and height for every month in both treatments and the energy and protein requirements (three plots/treatment) covered by the estimated consumption of the forage are presented in Table 1, while the chemical composition of the pastures is presented in Table 2.

Table 1 Mean forage availability, forage height (three plots/treatment), and calculated energy and protein balances in ewes on high or low forage allowance of natural grassland from 23 days before conception until day 70 or 122 of gestation

\begin{tabular}{|c|c|c|c|c|c|c|c|c|}
\hline \multirow{2}{*}{$\begin{array}{l}\text { Season } \\
\text { Months, days relative to day } \\
\text { of conception }\end{array}$} & \multirow{2}{*}{\multicolumn{2}{|c|}{$\begin{array}{l}\text { Forage availability, } \\
\text { kg DM/ha }\end{array}$}} & \multirow{2}{*}{\multicolumn{2}{|c|}{ Forage height, $\mathrm{cm}$}} & \multicolumn{4}{|c|}{ Balance (\%) } \\
\hline & & & & & \multicolumn{2}{|c|}{ Energy ${ }^{1}$} & \multicolumn{2}{|c|}{ Protein $^{2}$} \\
\hline Autumn & HFA & LFA & HFA & LFA & HFA & LFA & HFA & LFA \\
\hline March-April, days -23 to 24 & 1599 & 1599 & 10.0 & 10.0 & 136 & 106 & 108 & 102 \\
\hline May, days 25 to 58 & 1753 & 1233 & 15.5 & 11.6 & 126 & 83 & 99 & 70 \\
\hline \multicolumn{9}{|l|}{ Winter } \\
\hline June, days 59 to 96 & 1523 & 959 & 13.4 & 9.6 & 102 & 74 & 83 & 67 \\
\hline July, days 97 to 122 & 1246 & 763 & 13.0 & 7.9 & 108 & 84 & 69 & 50 \\
\hline
\end{tabular}

HFA: high forage allowance, LFA: low forage allowance

1 Metabolizable energy requirements obtained from NRC tables (2007)

${ }^{2}$ Crude protein requirements obtained from NRC tables (1985) 
Table 2 Mean chemical composition (three plots/treatment) of high or low forage allowance of natural grassland grazed by ewes from 23 days before conception until day 70 or 122 of gestation

\begin{tabular}{|c|c|c|c|c|c|c|c|c|c|c|}
\hline \multirow{2}{*}{$\begin{array}{l}\text { Season } \\
\text { Months, days relative } \\
\text { to day of conception } \\
\text { Autumn }\end{array}$} & \multicolumn{2}{|c|}{$\mathrm{DM}, \%$} & \multicolumn{2}{|c|}{$\mathrm{CP}, \%$} & \multicolumn{2}{|c|}{ NDF, \% } & \multicolumn{2}{|c|}{ ADF, \% } & \multicolumn{2}{|c|}{ Ash, \% } \\
\hline & HFA & LFA & HFA & LFA & HFA & LFA & HFA & LFA & HFA & LFA \\
\hline March, days -23 to 0 & 92.5 & 92.5 & 9.8 & 9.8 & 73.9 & 73.9 & 35.3 & 35.3 & 7.9 & 7.9 \\
\hline \multicolumn{11}{|l|}{ Winter } \\
\hline June, days 59 to 96 & 90.6 & 90.1 & 8.3 & 8.2 & 70.2 & 73.1 & 34.0 & 35.4 & 6.5 & 6.1 \\
\hline July, days 97 to 122 & 91.7 & 90.5 & 6.9 & 6.5 & 75.1 & 75.9 & 37.5 & 37.6 & 6.7 & 6.3 \\
\hline
\end{tabular}

DM: dry matter, CP: crude protein, NDF: neutral detergent fibre, ADF: acid detergent fibre, HFA: high forage allowance, LFA: low forage allowance

Bodyweights and BCS of the ewes were recorded on days $23,0,24,58,96,122$, and 145 of gestation. On day 70 , the same parameters were recorded from the ewes that were euthanized (18 ewes). The BW of all the ewes was corrected for estimated fleece weight (Gastel et al., 1995) and foetal weight (Koong et al., 1975).

Foetal weight was recorded on excision from the uterus, and the foetal carcass was weighed after removal of the head and all the viscera. The heart and kidneys were weighed, and the penis length was measured from the cranial insertion of the scrotum to the tip of the prepuce. Scrotal base and length (lateral view, from scrotum insertion to distal end of scrotum) were recorded with digital pictures.

Newborn lambs were weighed before euthanasia. Directly after euthanasia, the thoracic perimeter (perimeter at the sternal xiphoid process), cranio-caudal length (distance between the atlanto-occipital and the sacrococcygeal joints), left hind limb length (distance between the ischiatic tuberosity and the femorotibial joint) and perimeter (maximum perimeter at hind limb length) were measured. The growth index was based on the Gootwine index (Gootwine, 2013) $\left(\mathrm{Gl}=\right.$ birth BW/cranio-caudal length $\left.{ }^{1.5}\right)$. Liver, adrenal glands, kidneys, heart, encephalon, brain, cerebellum, testes, and scrotum skin were removed and weighed. The external genitalia were measured as described for the foetuses. The carcass weight was also recorded, and the brain/liver ratio was calculated.

Data were analysed in a completely randomized block design using SAS Systems software (SAS 9.0V, SAS Institute, Cary, NC, USA). The BW and BCS of the ewes were analysed as repeated measures using the MIXED procedure (PROC MIXED), with day as the repeated effect. The model included treatments (HFA vs LFA), time, and their interaction as fixed effects, and the block as a random effect. Initial values (day -23) were used as covariates. Data from day 70 foetus mothers were analysed separately to compare their BW and BCS at slaughter using a mixed (PROC MIXED) model with the treatment as the fixed effect and block as random effect.

Foetuses, newborn lambs, their carcass weights, and the weight of the various organs, newborn lamb body dimensions and the size of the external genitalia were analysed using a mixed model (PROC MIXED). The adjusted models included the treatments as fixed effects and the block as a random effect. The interaction between treatment and block was included in all the models as a random effect. When the estimate of the covariance parameter was zero or near zero, it was removed from the model. To determine whether differences between treatments in foetal or newborn lamb organ measurements were independent of foetal or newborn lamb weight, between treatments, the models were re-analysed, including the foetal or the newborn lamb BW as a covariate.

Data were expressed as least square means \pm SE. Statistical differences were considered significant when $P \leq 0.05$, and as tendencies when $0.05<P \leq 0.10$.

\section{Results and Discussion}

The HFA ewes were heavier and their BCS was higher than those of ewes on the LFA treatment (HFA: $47.3 \pm 0.3 \mathrm{~kg}$ and $2.70 \pm 0.02$ versus LFA: $45.2 \pm 0.3 \mathrm{~kg}, 2.53 \pm 0.02$, BW and BCS, respectively $)(P<0.0001$ for either variable). Both variables varied over time $(P<0.0001)$, and there was an interaction between treatment and time (BW: $P=0.005$; BCS: $P=0.0004$ ). The results from the current study showed that the BW and BCS of ewes for both treatment groups increased $(P<0.0001$ and 0.005 , respectively) from day -23 to day 0 . On day 0 
ewes on the HFA treatment were heavier than ewes on the LFA treatment $(P=0.04)$ (Figure $1 \mathrm{a})$, and their BCS was higher $(P=0.05)$ (Figure $1 \mathrm{~b})$. For the remainder of the trial, the ewes on the HFA treatment were heavier and had a higher BCS than ewes on the LFA treatment, the only exception being BCS on day 122 . At slaughter on day 70 the HFA ewes again were heavier with a higher BCS than the LFA ewes $(P=0.001$ and 0.0001 , respectively.
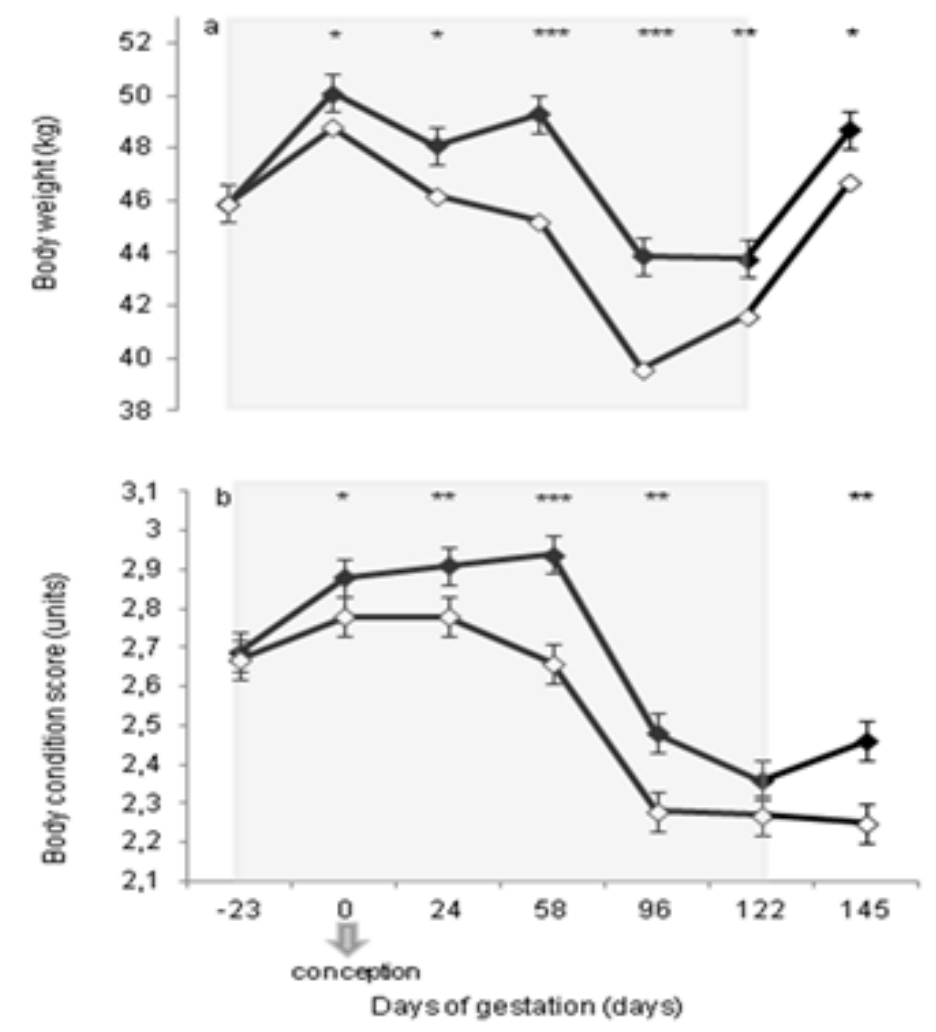

Figure 1 Bodyweight (a) and body condition score (b) of 36 multiparous ewes carrying single male pregnancies that grazed on high (HFA; $)$ or low (LFA; $\diamond)$ forage allowance on natural grassland from 23 days before conception until day122 $(\mathrm{a}, \mathrm{b})$ of gestation

The shaded area indicates the period that the ewes grazed on different forage allowances. Asterisks indicate significant differences between groups on the same gestation day: ${ }^{*} P<0.05 ;{ }^{* \star} P<0.01,{ }^{* \star \star} P<0.001$

Foetuses (Table 3) from ewes in the HFA treatment tended to be heavier $(P=0.08)$ than those in the LFA treatment. Foetuses from HFA had higher heart weight, penis, scrotal and scrotal base lengths than LFA foetuses $(P=0.04,0.001,0.001$ and 0.001 , respectively). When foetal BW was included as a covariate in the model, the difference in foetal heart weight disappeared, but the other differences persisted $(P=0.01$ for all the other variables). No differences in kidneys weight were found between groups $(P \geq 0.10)$. 
Table 3 Foetal and organs weights and size of external genitalia of foetuses from ewes that grazed on high or low forage allowance on natural grassland from 23 days before conception until day 70 of gestation

\begin{tabular}{lrrrr}
\hline & HFA & LFA & SE & \multicolumn{1}{c}{$P$-Value } \\
\hline Foetal weight, g & 151.30 & 143.90 & 5.20 & 0.08 \\
Heart weight, g & 1.28 & 1.13 & 0.05 & 0.04 \\
Penis length, cm & 2.49 & 1.99 & 0.09 & $>0.01$ \\
Scrotal length, cm & 1.34 & 1.08 & 0.05 & $>0.01$ \\
Scrotal base length, cm & 1.07 & 0.87 & 0.03 & $>0.01$ \\
\hline
\end{tabular}

HFA: high forage allowance, LFA: low forage allowance

At birth (Table 4), newborn lambs from HFA ewes were heavier than those of LFA ewes $(P=0.008)$. The treatments did not affect foetal carcass weight (HFA: $80 \mathrm{~g}$ vs LFA: $76.9 \mathrm{~g}$ ). However, the carcasses of newborn lambs in the HFA treatment were heavier $(P=0.0005)$ than those from the LFA treatment. This difference was also observed when birth BW was included in the model as a covariate $(P=0.02)$. The thoracic and hindlimb perimeters tended to be longer $(P=0.08$ and $P=0.07$, respectively) and hindlimbs were longer $(P=0.02)$ in HFA than in LFA newborn lambs, but no differences between groups were found in cranio-caudal length (HFA: 47.6 $\mathrm{cm}$ vs LFA: $46.9 \mathrm{~cm}$ ). When birth BW was included in the model as a covariate, most tendencies disappeared, but there was still a tendency in hindlimb length $(P=0.07)$. The Gootwine Index was higher in HFA than in LFA newborn lambs $(P=0.02)$. Newborn lambs from HFA had higher liver, kidneys, testes, adrenal gland weights, and penis length ( $P=0.02,0.04,0.02,0.02$ and 0.05 , respectively) than LFA lambs, and tended to have higher scrotal weight and scrotal base length ( $P=0.07$ and 0.06 , respectively) than LFA lambs, but there were no differences in scrotal length between groups $(4.75 \mathrm{~cm} v s$ LFA: $4.42 \mathrm{~cm})$. When birth BW was included as a covariate in the model, only the adrenal gland weight difference persisted $(P=0.04)$. The brain/liver ratio was lower in HFA than in LFA newborn lambs $(P=0.02$, Table 4). The treatments did not affect the weights of the brain, cerebellum, encephalon and heart of the newborn lambs (HFA: $43.00 \mathrm{~g}$ vs LFA: $42.60 \mathrm{~g}$, HFA: $6.07 \mathrm{~g}$ vs LFA: $6.10 \mathrm{~g}$, HFA: $57.80 \mathrm{~g}$ vs LFA: $57.00 \mathrm{~g}$, and HFA: $42.80 \mathrm{~g}$ vs LFA: $39.30 \mathrm{~g}$, respectively).

The treatment applied to the LFA ewes induced IUGR in their offspring, as those lambs had lower birth BW and GI, greater brain/liver ratio and modifications in their body proportions. The effects on organ growth differed according to the organ and to the stage of gestation, demonstrating that the foetus assigns different priority levels to the development of each organ. In general, as hypothesized, the growth of the central organs was prioritized at the expense of the peripheral organs. The lack of differences in the brains of newborn lambs and the weight of the cerebellum indicates that the central nervous system received high priority during intrauterine growth when the dam nutrition was restricted. This is consistent with the findings of Nathanielsz and Hanson (2003), who proposed that under hypoxic conditions the foetus prioritizes the oxygen and nutrient supply to vital organs, mainly the brain, heart, and adrenal glands, by redistributing blood flow. However, although the current results were consistent with the 'brain-sparing' theory, it is interesting that the profiles of the prioritization varied along gestation. In effect, the heart weight reduction that was observed in 70-day-old LFA foetuses disappeared in newborn lambs. This might be associated with the exponential growth of the foetus, and thus with a more important role of the heart owing to the increase in circulatory demands. Similarly, Pillai et al. (2017) reported that a restriction of $60 \%$ in the total digestible nutrients did not affect heart length, width and weight in newborn lambs. Hence, the current results suggested that those mechanisms that underlie heart prioritization during foetal development might be more active during the second half of gestation, when foetal cardiovascular demands become greater. Nevertheless, the authors did not perform histomorphological or functional studies and, although SNC weight was not affected, cognitive development may have been affected. For example, Hernández et al. (2010) reported that periconceptional undernutrition of the dams could suppress the behavioral responses to social isolation in lambs, even into their adulthood. Moreover, in humans, IUGR is related to cognitive development delay (Nyaradi et al., 2013). Similarly, subnutrition during pregnancy affected the cardiovascular function in three-year-old sheep (Gopalakrishnan et al., 2004) and increased the risks of cardiac disease in adult humans (Barker et al., 1993). 
Table 4 Birth, carcass and organs weights, body dimensions and size of external genitalia of newborn lambs from ewes that grazed on high or low forage allowance on natural grassland from 23 days before conception until day 122 of gestation

\begin{tabular}{lrrrr}
\hline & HFA & LFA & SE & $P$-Value \\
\hline Birth weight, kg & 5.10 & 4.50 & 0.10 & $>0.01$ \\
Carcass weight, kg & 2.45 & 2.07 & 0.06 & $>0.01$ \\
Hindlimb perimeter, cm & 20.80 & 19.80 & 0.30 & 0.07 \\
Hindlimb length, cm & 12.00 & 11.20 & 0.20 & 0.02 \\
Thoracic perimeter, cm & 39.10 & 37.30 & 0.90 & 0.08 \\
Growth index & 15.70 & 14.00 & 0.40 & 0.02 \\
Liver weight, g & 126.80 & 100.90 & 6.90 & 0.02 \\
Kidney weight, g & 30.50 & 25.50 & 1.60 & 0.04 \\
Adrenal glands weight, g & 0.97 & 0.82 & 0.04 & 0.02 \\
Penis length, cm & 7.55 & 6.27 & 0.42 & 0.05 \\
Scrotal base, cm & 3.49 & 2.88 & 0.21 & 0.06 \\
Testes weight, g & 1.92 & 1.62 & 0.08 & 0.02 \\
Scrotal weight, g & 9.80 & 8.20 & 0.60 & 0.07 \\
Brain/Liver ratio & 0.35 & 0.43 & 0.02 & 0.02 \\
\hline
\end{tabular}

HFA: high forage allowance, LFA: low forage allowance

${ }^{1}$ Growth index (GI): birth BW/cranio-caudal length ${ }^{1.5}$ (Gootwine, 2013)

Although kidneys and liver were lighter in the LFA group, it can be speculated that, according to the differences in the relative importance (differences when birth BW was included and not included as a covariate), the nutrient prioritization was more important for the kidneys than for the liver. In the present work, not only were kidneys affected by maternal nutrition, but adrenal glands were prioritized less than kidneys and liver. Although the current results contradict those of Pillai et al. (2017), who reported that nutrient restriction of pregnant ewes did not affect the weights of kidneys and adrenal glands, they agree with those of Hernández et al. (2010), who reported that four- and 18-month-old lambs from undernourished ewes responded to social isolation with lower increases of cortisol. Tchirikov et al. (2002) reported a reduction of cell proliferation in the foetal liver, and consequently a lower liver to bodyweight relationship in pregnant ewes, increasing the foetal liver bypass by placing a $4 \mathrm{~mm}$ stent in the ductus venosus. Therefore, the current findings of reduced foetal liver weight in LFA lambs could be because of an increase in liver perfusion bypass triggered under nutrient limited conditions.

On the other hand, external genitalia were less developed under IUGR, and this cannot be explained only by differences in foetal weight. Thus, the authors suggest that foetuses did not prioritize nutrient delivery to the external genitalia on exposure to nutrient restriction. Differences in size of external genitalia (scrotal length) are linked to the size of the mother on day 140 of gestation, but not to the plane of nutrition of the mothers (Kenyon et al., 2011). Therefore, according to current knowledge, this was the first report to relate undernutrition of the mothers to smaller external genitalia in the ovine foetus (such as penis length). The differences in testicular weight in newborn lambs agreed with the authors' previous report (Bielli et al., 2001). However, the differences disappeared when the authors included BW as a covariate, suggesting that testicular growth was affected in the same proportion as the lamb itself. The current results suggest strongly that testes were prioritized more than external genitalia. This seems logical, since testes, and not external genitalia, are producers of gametes and consequently are more important for reproductive success.

It is well known that IUGR affects carcass weight (Asmad et al., 2011; Jaquiery et al., 2012). The nutritional restriction in the LFA group during the first half of gestation was not enough to induce changes in the total weight of the carcass (mainly muscles and bones). However, when the restriction was extended to 23 days 
before lambing, there was a negative impact on the carcass weight. Lighter lambs had lighter carcasses, as expected, but according to the covariance analyses, the nutritional restriction strengthened this effect. It is possible that since the second half of gestation, which coincided with the increase of foetal demands (Koong et al., 1975), the LFA forced a prioritization of the vital organs at the expense of the muscles and bones. Moreover, this effect was not compensated, even with 23 days of high nutrition until birth.

A low forage allowance until day 70 of gestation probably did not result in a severe nutrient restriction because foetal weight tended to be lower only in the LFA group. This is consistent with the findings of Osgerby et al. (2002) and Vonnahme et al. (2003), who reported that the consequences of undernutrition in foetal weight differed according to the magnitude of the restriction. In the current study, ewes continued to graze on a low forage allowance, the nutritional value of which generally decreased in winter, so the level of subnutrition became more severe from this period, resulting in altered newborn birth BW. On the other hand, Kenyon and Blair (2014) proposed that moderate undernutrition during early gestation can be compensated by improving the nutritional conditions during the last third of gestation. However, according to the present results, the effectiveness of the compensatory effect seems to depend on the duration of the nutritional improvement, since 23 days of improved nutrition were not enough to compensate the negative effect induced by the current treatment on birth BW.

\section{Conclusion}

A low forage allowance of natural grasslands resulted in IUGR and differential growth of organs in 70-dayold foetuses and newborn lambs. Growth of the central organs was generally prioritized at the expense of peripheral organs. Thus, the proposed order of priority (greatest to least) was central nervous system, heart, metabolic organs and testes, and carcass and external genitalia. Further studies should be conducted to validate this proposed order of prioritization. Novel studies should focus on identification of histological changes and biochemical mechanisms that are involved in these organ-specific developmental alterations.

\section{Acknowledgements}

The authors acknowledge C. Mantero, Director of the Estación Experimental Bernardo Rosengurtt, and E. Lena, X. Viera, I. Sosa, C. García and B. Martínez for animal management during the experimental work. The authors also thank C. López Mazz and M. Regueiro for ultrasound diagnosis, and P. Genovese and V. Riaño for their help during sampling. M. Carriquiry for assistance with the statistical analysis. Financial support was provided by Fondo María Viñas (Agencia Nacional de Investigación e Innovación; Uruguay, FMV_2_2011_1_7121). First author received a scholarship from Agencia Nacional de Investigación e Innovación; Uruguay (POS_NĀC_2012_1_9235).

\section{Authors' Contributions}

MJA, $A B$, and RPC conceived and designed the experiments. MJA, AFM, AAO, ALP, and RPC performed the field experiments. MJA, AB, JI, AAO, and RPC contributed with the sampling work. MJA, and RPC analysed the data. RPC, AB, and $A A O$ contributed with materials and analysis tools. $A B, R P C, R U$, JI, and MJA wrote the manuscript. RU, AB, RPC, and AFM contributed with the critical reading and participated in correcting the manuscript. All the authors approved the final version of the manuscript.

\section{Conflict of Interest Declaration}

The authors declare that they have no conflict of interest.

\section{References}

AOAC, 2007. Official methods of analysis. 18th edition. Association of Official Analytical Chemists, Washington DC, USA.

AOCS, 2012. Official methods and recommended practices. 103rd edition. American Oil Chemists' Society, Long Beach, California, USA.

Asmad, K., Paten, A.M., Loureiro, M.F.P., Kenyon, P.R., Pain, S.J., Parkinson, T.J., Pomroy, W.E., Scott, I. \& Blair, H.T., 2011. Brief communication: The effects of dam nutrition during pregnancy on the growth of male offspring. Proc. N.Z. Soc. Anim. Prod. 71, 59-61.

Barker, D.J.P., Gluckman, P.D., Godfrey, K.M., Harding, J.E., Owens, J.A. \& Robinson, J.S., 1993. Fetal nutrition and cardiovascular disease in adult life. Lancet 341, 938-941.

Barker, D.J.P., 2003. The developmental origins of adult disease. Eur. J. Epidemiol. 18, 733-766.

Bermúdez, R. \& Ayala, W., 2005. Producción de forraje de un campo natural de la zona de lomadas del este. En: Serie Técnica 151: Seminario de actualización técnica en manejo de campo natural. R. Miller \& M.M. Albicette, INIA, Montevideo, Uruguay. Pp. 33-40 (in Spanish).

Berretta, E.J., 1993. Registros de producción de pasturas. En: Serie Técnica 39: Registros físicos en la producción pecuaria. Ed: Berretta, E.J., Guerra, J.C. \& de Mattos, D., INIA, Montevideo, Uruguay. pp. 9-14 (in Spanish) 
Bielli, A., Katz, H., Pedrana, G., Gastel, M.T., Moraña, A., Castrillejo, A., Lundeheim, N., Forsberg, M. \& Rodriguez-Martinez, $\mathrm{H}$., 2001. Nutritional management during fetal life and postnatal life, and the influence on testicular stereology and Sertoli cell numbers in Corriedale rams. Small Rumin. Res. 40, 62-71.

Calkins, K. \& Devaskar, S.U., 2011. Fetal origins of adult disease. Curr. Probl. Pediatr. Adolesc. Health Care 41, $158-176$.

Caton, J.S. \& Hess, B.W., 2010. Maternal plane of nutrition: Impacts on fetal outcomes and postnatal offspring responses. Invited Review. Proc. 4th Graz. Livest. Nutr. 104-122.

Fowden, A.L. \& Forhead, A.J., 2004. Endocrine mechanisms of intrauterine programming. Reproduction 127, $515-526$.

Freitas-de-Melo, A., Ungerfeld, R., Hötzel, M.J., Abud, M.J., Álvarez-Oxiley, A., Orihuela, A., Damián, J.P. \& Pérez-Clariget, R., 2015. Mother-young behaviours at lambing in grazing ewes: Effects of lamb sex and food restriction in pregnancy. Appl. Anim. Behav. Sci. 168, 31-36.

Freitas-de-Melo, A., Terrazas, A., Ungerfeld, R., Hötzel, M.J., Orihuela, A. \& Pérez-Clariget, R., 2017. Influence of low pasture allowance during pregnancy on the attachment between ewes and their lambs at birth and during lactation. Appl. Anim. Behav. Sci. (forthcoming)

Fundación Española para el Desarrollo de la Nutrición Animal (2010). Tablas FEDNA. Glicerina y Salvado de Arroz Blanco. http://www.fundacionfedna.org (in Spanish)

Gao, F., Yingchun, L., Lingyao, L., Ming, L., Chongzhi, Z., Changjin, A. \& Xianzhi, H., 2014. Effects of maternal undernutrition during late pregnancy on the development and function of ovine fetal liver. Anim. Reprod. Sci. 147, 99-105.

Gastel, T., Bielli, A., Perez, R., Lopez, A., Castrillejo, A., Tagle, R., Franco, J., Laborde, D., Forsberg, M. \& RodriguezMartinez, H., 1995. Seasonal variations in testicular morphology in Uruguayan Corriedale rams. Anim. Reprod. Sci. 40, 59-75.

Gootwine, E., 2013. Meta-analysis of morphometric parameters of late-gestation fetal sheep developed under natural and artificial constraints. J. Anim. Sci. 91, 111-119.

Gopalakrishnan, G.S., Gardner, D.S., Rhind, S.M., Rae, M.T., Kyle, C.E., Brooks, A.N., Walker, R.M., Ramsay, M.M., Keisler, D.H., Stephenson, T. \& Symonds, M.E., 2004. Programming of adult cardiovascular function after early maternal undernutrition in sheep. Am. J. Physiol. Regul. Integr. Comp. Physiol. 287, 12-20.

Haydock, K.P. \& Shaw, N.H., 1975. The comparative yield method for estimating dry matter yield of pastures. Aust. J. Exp. Agric. Anim. Husb. 5, 663-670.

Hernández, C.E., Matthews, L.R., Oliver, M.H., Bloomfield, F.H. \& Harding, J.E., 2010. Effects of sex, litter size and periconceptional ewe nutrition on offspring behavioural and physiological response to isolation. Physiol. Behav. 101, 588-594.

Jaquiery, A.L., Oliver, M.H., Honeyfield-Ross, M., Harding, J.E. \& Bloomfield, F.H., 2012. Periconceptional undernutrition in sheep affects adult phenotype only in males. J. Nutr. Metab. 2012, 1-7.

Jefferies, B.C., 1961. Body condition scoring and its use in management. Tasmanian J. Agr. 32, 19-21.

Kenyon, P.R. \& Blair, H.T., 2014. Foetal programming in sheep - Effects on production. Small Rumin. Res. 118, 16-30.

Kenyon, P.R., Van der Linden, D.S., Jenkinson, C.M.C., Morris, S.T., Mackenzie, D.D.S., Peterson, S.W., Firth, E.C. \& Blair, H.T., 2011. The effect of ewe size and nutritional regimen beginning in early pregnancy on development of singleton foetuses in late pregnancy. Livest. Sci. 142, 92-98.

Koong, L.J., Garrett, W.N., Rattray, P.V., 1975. A Description of the dynamics of fetal growth in sheep. J. Anim. Sci. 41, 1065-1068.

Metges, C.C., Lang, I.S., Hennig, U., Brüssow, K.P. \& Kanitz, E., 2012. Intrauterine growth retarded progeny of pregnant sows fed high protein: low carbohydrate diet is related to metabolic energy deficit. PLOS ONE 7, e31390.

Nathanielsz, P.W. \& Hanson, M.A., 2003. The fetal dilemma: Spare the brain and spoil the liver. J. Physiol. $548,333$.

NRC, 1985. Nutrient requirements of sheep. 6th edition. National Academy Press, Washington, DC, USA.

NRC, 2007. Nutrient requirements of small ruminants: Sheep, goats, cervids and New World camelids. National Academy Press, Washington, DC, USA.

Nyaradi, A., Li, J., Hickling, S., Foster, J. \& Oddy, W.H., 2013. The role of nutrition in children's neurocognitive development, from pregnancy through childhood. Front. Hum. Neurosci. 7, 97.

Osgerby, J.C., Wathes, D.C., Howard, D. \& Gadd, T.S., 2002. The effect of maternal undernutrition on ovine fetal growth. J. Endocrinol. 173, 131-141.

Pillai, S.M., Jones, A.K., Hoffman, M.L., NcFadden, K.K., Reed, S.A., Zinn, S.A. \& Govoni, K.E., 2017. Fetal and organ development at gestational days 45, 90, 135 and at birth of lambs exposed to under - or over - nutrition during gestation. Transl. Anim. Sci. 1, 16-25.

Rudolph, A.M., 1984. The fetal circulation and its response to stress. J. Dev. Physiol. 6, 11-19.

Sargison, N.D., 2007. Pregnancy toxaemia. In: I.D. Aitken (ed). Diseases of sheep. Blackwell Publishing Ltd, Oxford, UK. pp. 359-363.

Sollenberger, L.E., Moore, J.E., Allen, V.G. \& Pedreira, C.G.S., 2005. Reporting forage allowance in grazing experiments. Crop Sci. 45, 896-900.

Tchirikov, M., Kertschanska, S., Stürenberg, H.J. \& Schröder, H.J., 2002. Liver blood perfusion as a possible instrument for fetal growth regulation. Placenta 23, S153-S158. 
Torres-Rovira, L., Tarrade, A., Astiz, S., Mourier, E., Perez-Solana, M. \& de la Cruz, P., 2013. Sex and breed-dependent organ development and metabolic responses in foetuses from lean and obese/leptin resistant swine. PLOS ONE 8 , e66728. DOI: 101371/journal.pone.0066728.

Van Soest, P.J., Robertson, J.B. \& Lewis, B.A., 1991. Methods for dietary fiber, neutral detergent fiber, and nonstarch polysaccharides in relation to animal nutrition. J. Dairy Sci. 74, 3583-3597.

Vonnahme, K.A., Hess, B.W., Hansen, T.R., McCormick, R.J., Rule, D.C., Moss, G.E., Murdoch, W.J., Nijland, M.J., Skinner, D.C., Peter W Nathanielsz, P.W. \& Ford, S.P., 2003. Maternal undernutrition from early- to mid-gestation leads to growth retardation, cardiac ventricular hypertrophy, and increased liver weight in the fetal sheep. Biol. Reprod. 69, 133-140.

Vuguin, P.M., 2007. Animal models for small for gestational age and fetal programming of adult disease. Horm. Res. 68, 113123.

Xu, Y., Williams, S.J., O’Brien, D. \& Davidge, S.T., 2006. Hypoxia or nutrient restriction during pregnancy in rats leads to progressive cardiac remodeling and impairs postischemic recovery in adult male offspring. Express summary. FASEB J. 20, 1251-1253. 